\title{
Bronchiolitis obliterans with organising pneumonia: outcome
}

\author{
Ulrich Costabel, Josune Guzman, Helmut Teschler \\ Abteilung Pneumologie/Allergologie, Ruhrlandklinik, Essen, Germany
}

Introductory article

\section{Rapidly progressive bronchiolitis obliterans with organising pneumonia}

\begin{abstract}
Andrea J Cohen, Talmadge E King Jr, Gregory P Downey
Bronchiolitis obliterans with organising pneumonia (BOOP) is a distinct clinical pathologic syndrome. Most patients experience a good response to therapy, and death from progressive BOOP is uncommon. This report describes the clinical features, etiologic factors, pathologic findings, and outcome of 10 patients with rapidly progressive BOOP that was characterised by severe respiratory failure. The major clinical manifestations were dyspnea, cough, fever, crackles on chest examination, and hypoxemia at rest. Underlying conditions or exposures included connective-tissue disease, exposure to birds, and chronic nitrofurantoin therapy. All patients had the characteristic histopathologic findings of BOOP. However, at autopsy in six patients, the predominant histologic pattern was that of alveolar septal inflammation and fibrotic honeycombing. Seven patients died and three patients survived but had persistent pulmonary dysfunction despite aggressive care. In two patients BOOP has progressed, with severe chronic respiratory decompensation. Thus, there is a subset of patients with BOOP who present with a fulminant course leading to death or chronic severe fibrosis and marked impairment of lung function. In addition, the histologic picture of BOOP may be a manifestation of early lung injury that can resolve or progress rapidly to alveolar septal inflammation, end-stage fibrosis, and honeycombing.
\end{abstract}

(Am J Respir Crit Care Med 1994;149:1670-5)

Bronchiolitis obliterans with organising pneumonia (BOOP) is a clinicopathological syndrome which has become increasingly recognised during the past decade. Several studies have been performed in larger collections of patients, ${ }^{1-10}$ and increasing numbers of case reports on the association of this syndrome with underlying conditions have been reported. ${ }^{11}$ Clinically, the entity usually starts with a subacute influenza-like illness, followed by cough, progressive dyspnoea, and weight loss. Radiographically, the disease is characterised by multiple patchy alveolar infiltrates not responsive to antibiotics, and functionally by hypoxaemia and a restrictive ventilatory defect. ${ }^{1-11}$ Histopathologically, buds of granulation tissue are focally seen in respiratory bronchioles and in alveolar ducts, with extension of the organisation into the alveoli (organising pneumonia). ${ }^{1412}$ The involvement of the bronchioles may sometimes be missed in biopsy samples, and the term "cryptogenic organising pneumonitis (COP)" may then be more appropriate. ${ }^{1314}$ An interstitial mononuclear cell infiltrate and accumulation of foam cells in the alveolar spaces are also frequently observed. The response to corticosteroid treatment is excellent in most cases. ${ }^{168913}$

\footnotetext{
History

The story of BOOP started in 1985 when Epler et al coined the term. ${ }^{1}$ They analysed 2500 reports of open lung biopsies and searched for the presence of bronchiolitis obliterans in the description. They found 67 cases for analysis, including 57 with histological reports showing both bronchiolitis obliterans and organising pneumonia (BOOP cases), and 10 with lesions of bronchiolitis obliterans only but no parenchymal involvement. Of the 57 cases of BOOP, 50 were idiopathic (no underlying cause or disease), and seven were associated with causes or underlying conditions (two with inhalation injury, five with connective tissue disease). The merit of this study was to make clinicians and pathologists aware of this distinct entity within the spectrum of infiltrative lung diseases, to describe the clinical picture in detail, and to provide good arguments
} 
that idiopathic BOOP (which has been confused with idiopathic pulmonary fibrosis (IPF) or usual interstitial pneumonitis (UIP)) has a much better prognosis and that a clear distinction would be important.

However, idiopathic BOOP is not a new lesion and similar cases have been previously described under different synonyms - for example, bronchiolitis interstitial pneumonia (BIP) by Liebow and Carrington ${ }^{15}$ in their classification of the chronic interstitial pneumonias, or cryptogenic organising pneumonia (COP) by Davison et al, ${ }^{13}$ who were the first to recognise the association of the distinct clinical feature with the pathological lesion and also to report the dramatic response to prednisolone. As early as 1901 , Lange ${ }^{16}$ was the first to describe the histological changes of bronchiolitis obliterans in a necroscopic study of two patients. In retrospect, his histological description is more like BOOP than bronchiolitis obliterans.

\section{Causes}

BOOP may be idiopathic or associated with underlying conditions. ${ }^{17-40}$ Most cases of BOOP are idiopathic, but this clinicopathological syndrome has been described in association with many different factors, particularly collagen vascular disease and administration of drugs (box). In Epler's original series 50 of 57 cases (88\%) were idiopathic, five were associated with connective tissue disorders, and two with acute inhalation injury. Chandler et al collected 24 cases of BOOP when reviewing open lung biopsy specimens from the pathology files; $17(71 \%)$ were idiopathic and seven had underlying connective tissue disease including rheumatoid arthritis, polymyositis, mixed connective tissue disease, and systemic lupus erythematosus. In a Japanese series ${ }^{7} 21$ of 29 cases $(72 \%)$ were idiopathic, five were associated with collagen vascular disease including four with rheumatoid arthritis and one with Behçet's disease, two had chronic thyroiditis, and one had alcoholic liver cirrhosis. Thus, between $70 \%$ and $90 \%$ of all cases of BOOP reported in larger studies were idiopathic.

Some conditions may show the histopathological pattern of BOOP in biopsy specimens, often in addition to other condition-specific histological lesions, without the typical clinical presentation of the BOOP syndrome. Such conditions include organising infections, organising diffuse alveolar damage, exposure to toxic gases and fumes, extrinsic allergic alveolitis, organising chronic eosinophilic pneumonia, Wegener's granulomatosis, bronchiectasis, and tissue reactions around abscesses, infarcts, and tumours. ${ }^{12}$ These conditions should not be misdiagnosed as the clinicopathological entity of BOOP.

\section{BOOP versus $\mathrm{BO}$}

BOOP should not be confused with pure bronchiolitis obliterans (BO).$^{41}$ Bronchiolitis obliterans (without organisation) is considerably less common than BOOP and is a totally different disease, both clinically and pathologically. This is a rare disorder of the small airways, histologically with stenotic, scarred, constrictive bronchiolitis (without intraluminal plugs or polyps), functionally characterised by airways obstruction; the chest radiograph is normal or shows hyperinflation and

\author{
Conditions associated with BOOP \\ Collagen vascular disease \\ Rheumatoid arthritis ${ }^{217}$ \\ Polymyositis and dermatomyositis ${ }^{218}$ \\ Systemic lupus erythematosus 319 \\ Progressive systemic sclerosis ${ }^{1320}$ \\ Sjögren's syndrome ${ }^{21}$ \\ Mixed connective tissue disease ${ }^{3}$ \\ Polymyalgia rheumatica ${ }^{22}$ \\ Behçet's disease ${ }^{7}$ \\ Polyarteritis nodosa ${ }^{23}$ \\ Ulcerative colitis ${ }^{24}$ \\ Drugs \\ Gold ${ }^{925}$ \\ Methotrexate ${ }^{26}$ \\ Naproxen ${ }^{22}$ \\ Sulphasalazine ${ }^{26}$ \\ Sulphamethoxypyridazine ${ }^{26}$ \\ Sulindac ${ }^{26}$ \\ Cephalosporins $^{926}$ \\ Amphotericin $\mathrm{B}^{26}$ \\ Amiodarone ${ }^{92627}$ \\ Acebutolol ${ }^{27}$ \\ Interferon ${ }^{28}$ \\ L-Tryptophan ${ }^{29}$ \\ Cocaine ${ }^{30}$ \\ Miscellaneous associations \\ HIV infection ${ }^{31}$ \\ Common variable immunodeficiency syndrome $\mathrm{e}^{32}$ \\ Radiation therapy ${ }^{33-36}$ \\ Myelodysplastic syndrome ${ }^{37}$ \\ Leukaemia $^{10}$ \\ Chronic thyroiditis? \\ Alcoholic cirrhosis ${ }^{7}$ \\ Malaria $^{38}$ \\ Bone marrow transplantation ${ }^{39}$ \\ Seasonal syndrome with cholestasis ${ }^{40}$
}

sometimes small nodules. ${ }^{42} 43$ The response to treatment is poor. The entity is associated with rheumatoid arthritis, ${ }^{42}$ other connective tissue disorders, ${ }^{44}$ graft versus host disease in bone marrow transplantation, ${ }^{4546}$ chronic rejection in lung transplantation, ${ }^{47}$ following penicillamine and gold treatment, ${ }^{4248}$ virus infections, ${ }^{49}$ toxic gas or fume inhalation, ${ }^{50}$ or aspiration..$^{50}$ Idiopathic bronchiolitis obliterans ${ }^{43}$ is very rare. It seems that most patients reported before 1985 in reality had BOOP, including the large series of Gosink et al. ${ }^{50}$

\section{Unfavourable outcome in BOOP?}

The introductory article by Cohen et al seems to cast some doubt on the concept that BOOP is a relatively benign condition with a good prognosis. ${ }^{51}$ Of 10 patients with biopsy-proven BOOP who presented with fulminant disease, only three would have been classified as idiopathic, seven had associated conditions (four connective tissue disease, two nitrofurantoin intake, one aspiration after surgery); seven patients died between seven weeks and nine months after the onset of their disease, two patients survived with severe physiological dysfunction, and one survived and had a complete clinical recovery. All patients were treated with corticosteroids, and five received additional immuno- 
suppressive treatment with cyclophosphamide $(\mathrm{n}=3)$ or azathioprine $(n=2)$.

A weakness of this study is that it is unclear how the patients were selected. The methods section describes the study design poorly. The study population is said to comprise 10 patients with biopsy-proven BOOP who presented "with a fulminant course". No criteria for a fulminant course are given. In the introduction the authors say that they "describe 10 patients with rapidly progressive respiratory failure attributed to BOOP who progressed to death or end-stage lung disease". This is not quite correct since one patient is alive after full recovery without progression to end-stage disease. Why this patient was included is not immediately obvious. Patients were evaluated between 1979 and 1992, so it was obviously a retrospective analysis. Clinical findings and follow up information were obtained from hospital and clinical records and from referring physicians, but later it is stated that the 10 patients were examined at the three centres that participated in the study; they were obviously not seen in one single institution. It is not mentioned in the paper how many necropsy records, biopsy reports, and/or clinical charts were screened in the three centres during 1979 and 1992 to detect 10 patients with rapidly progressive BOOP. It would have been useful to know the total number of patients diagnosed with BOOP in this period, including those with a benign course. Without such numbers being available, the conclusion by Cohen et al that the current concept of BOOP as a benign illness should be reconsidered seems premature and not justified by their paper. Assuming that each participating centre may have seen $30-50$ cases in the 14 years (that is, $2-4$ per year), then the three centres together should have seen $90-150$ in this period. This would mean that seven lethal cases were observed amongst $90-150$ cases of BOOP, giving an estimated mortality of $5-8 \%$. This fits well with reported figures, as outlined below.

\section{Outcome of BOOP in previous studies}

Several larger retrospective series comprising more than 10 patients are available and can be analysed. In Epler's original series ${ }^{1}$ the mean follow up period after biopsy of 48 patients with idiopathic BOOP was four years (range $2-10)$. Twenty nine $(60 \%)$ showed complete recovery, five of them without steroid therapy; $13(27 \%)$ were stabilised with some residual cough or dyspnoea; two $(4 \%)$ had progressive disease and were alive; two died from BOOP and two from other causes (pulmonary embolism, ruptured aneurysm). The five patients with BOOP and connective tissue disorders fared worse none recovered completely.

In Chandler et al's series ${ }^{2}$ of 24 cases (17 idiopathic, seven with collagen vascular disease) with a mean follow up of 3.5 years (range two months to eight years), nine patients $(38 \%)$ recovered completely, seven $(30 \%)$ recovered with residual disease, and three $(12 \%)$ died from BOOP. In another paper by the same group, a worse course was described in those with collagen vascular disease. $^{3}$

Guerry-Force $e t a l^{4}$ analysed 15 patients with BOOP, two of these associated with mixed connective tissue disease and one with a poorly defined eosinophilic vasculitis. The average follow up from diagnosis was 26 months (range 1-104). Improvement was seen in 11 patients $(73 \%)$, no improvement in two (both with collagen vascular disease), and death due to respiratory failure in two $(13 \%)$, one with collagen vascular disease.

An interesting report on idiopathic BOOP was published in 1989 by Cordier et al. ${ }^{5}$ These authors distinguished three groups of idiopathic BOOP according to the radiographic and CT appearance, and found that the groups had distinct clinical profiles and outcomes. Group $1(n=4)$ presented with multiple patchy and migratory infiltrates, all of them showing full recovery after corticosteroid treatment. Group $2(n=5)$ had solitary pulmonary involvement; all underwent surgical resection for diagnostic and therapeutic purposes and none relapsed. Group $3(n=7)$ had diffuse pulmonary involvement (four with interstitial and three with mixed alveolar/interstitial opacities), and only four showed improvement; three deteriorated and two died from BOOP, which represents $12 \%$ of their total BOOP population. Interestingly, patients in groups 1 and 2 had raised lymphocyte levels in bronchoalveolar lavage fluid in addition to increased neutrophil and eosinophil counts, whereas patients in group 3 had normal lymphocyte counts.

Finally, a series of 34 Japanese patients with idiopathic BOOP were followed for a period ranging from one month to seven years. ${ }^{6}$ The prognosis was excellent; nine $(26 \%)$ were cured and $24(71 \%)$ showed improvement. Only one patient $(3 \%)$ died 50 months after diagnosis.

If these studies are taken together, the mortality rate due to BOOP is $3-13 \%$. In three reports full recovery was poorer in BOOP associated with collagen vascular disease. ${ }^{134}$ One study showed that the radiographic interstitial pattern was associated with a poorer prognosis. ${ }^{5}$

\section{Predictive factors for outcome in BOOP}

The merit of the paper by Cohen $e t a \Gamma^{1}$ is to have drawn attention to the fact that BOOP may be a lethal disease in a minority of patients, an observation which is not immediately evident to those physicians who see patients with this rare disease only occasionally and may have experienced the characteristic dramatic response to corticosteroids in these few patients.

It may be important to analyse what the differences are between the subgroup of patients with rapidly progressive, often lethal, BOOP, and those with a benign course. Cohen et al have attempted to identify risk factors for rapidly progressive disease by looking at such differences.

\section{SYMPTOMS AND SIGNS}

It is clear that the period of symptoms before diagnosis must have been shorter in those selected as rapidly progressive patients with a mean of 6.5 weeks (range three days to two months) than in the historical "control" series with a mean of about three months (range two weeks to nine months). The symptoms and signs were similar, with cough, dyspnoea, fever, and crackles being present in most patients in most series. ${ }^{1-10}$ Clubbing was seen in only one of the 10 patients with rapidly progressive BOOP, as it is unusual in all studies contrasting BOOP with IPF. 


\section{CHEST RADIOGRAPHY}

The chest radiographic pattern could be an important factor in predicting prognosis in BOOP. The main radiographic finding of BOOP is bilateral patchy air space consolidation (alveolar pattern), often in a peripheral distribution. ${ }^{12101152}$ When larger series are compiled, this pattern is present in about $70 \%$ of patients. Such opacities may show a migratory nature, either in the primary event or in relapsing patients, as lesions develop in locations other than the primary manifestations. ${ }^{675354}$ In the Japanese series migratory infiltrates were common, being seen in $50 \%$ of patients. Less frequently, linear or nodular opacities (interstitial pattern) were observed. In larger series about $15 \%$ of patients showed a purely interstitial pattern, and in another $15 \%$ a mixed alveolar/interstitial pattern was seen. ${ }^{1-10}$

Interestingly, only four patients in the study of Cohen et $a F^{1}$ had patchy alveolar infiltrates, four had a mixed pattern, and two had interstitial opacities. A previous study ${ }^{5}$ had already suggested that the outcome was much better in patients with alveolar infiltrates (all nine recovered) than in those with interstitial or mixed opacities (three of seven progressed, two died).

\section{BRONCHOALVEOLAR LAVAGE (BAL)}

BAL may prove useful in predicting the outcome of BOOP. The profile of the differential cell count in BAL fluid has recently been assessed by several groups, ${ }^{8556}$ with remarkably similar results (table). BAL fluid usually shows a mixed cellularity, with the most consistent increase being seen in the percentage of lymphocytes, and also neutrophils and eosinophils in many cases. Other features are the frequent presence of foamy macrophages, mast cells, and plasma cells. In our study of 10 patients ${ }^{55}$ lymphocytosis was present in all patients, neutrophil levels were raised in four, and eosinophils in eight. The seven patients in the study by Cordier et at with alveolar opacities on chest radiography, all with a good prognosis, also had this mixed BAL profile with a mean increase in lymphocytes of $38 \%$, whereas those five patients with interstitial abnormalities who had a poor response to treatment showed no increase in lymphocytes (mean 6\%) but increases in neutrophils and eosinophils, thus showing a BAL pattern similar to that of IPF.

Five of the patients with rapidly progressive BOOP in the study of Cohen et $l^{51}$ underwent BAL. Significant increases were seen in the percentages of neutrophils in four patients (mean 40\%) and of eosinophils also in four patients (mean 10\%). Only one showed a lymphocytosis in the BAL fluid.

Taken together, these results suggest that a high lymphocyte count may indicate a good response to treatment, whereas an increase in neutrophils and/or eosinophils without an additional increase in lymphocytes may predict a poor response.

\section{HISTOPATHOLOGY}

Two of the patients in the study of Cohen et al, ${ }^{51}$ both with associated rheumatoid arthritis, showed features of BOOP and UIP on open lung biopsy. When necropsy was performed BOOP was no longer present, but UIP, diffuse alveolar damage, and honeycombing dominated the histological picture. Two other patients, initially with pure BOOP on open biopsy, showed UIP on necropsy, one of them also with honeycombing and resolving BOOP. These sequential histological observations give rise to several explanations: (1) BOOP could be a precursor of alveolar septal inflammation and might progress to UIP and honeycomb lung, this view being favoured by Cohen et al. (2) Two separate lesions (BOOP and UIP) may be coexisting, with resolution of the inflammatory lesions of BOOP following corticosteroid therapy, and progression of the UIP lesions to end-stage fibrosis. (3) The primary lesion might be UIP and the BOOP lesion just a secondary inflammatory process. This concept is probably valid in patients with connective tissue disease as the underlying condition, since the presence of both lesions in the same patient, with UIP as the primary and BOOP as the secondary lesion, has been described before in patients with rheumatoid arthritis. ${ }^{17}$

Whether the different histological features of the BOOP pattern itself may dominate the outcome is not known from currently available studies. It may be reasonable to speculate that those patients with older fibrotic connective tissue plugs do worse than those with fresher plugs mainly composed of fibrinoid and inflammatory cell clusters. Similarly, the outcome might be different in those patients with predominant bronchiolar involvement from those with excessive alveolar organisation.

\section{ASSOCIATED CONDITIONS}

Cohen $e t l^{51}$ discuss the possibility that prognosis may be worse in those patients with associated conditions since most of their patients with a fulminant course had such associations, including four with connective tissue disease and two who had taken nitrofurantoin, a drug not

\begin{tabular}{|c|c|c|c|}
\hline & $\begin{array}{l}\text { Costabel et al }{ }^{55} \\
(n=10) \\
\text { Mean (SD) }\end{array}$ & $\begin{array}{l}\text { Nagai et al }\left.\right|^{56} \\
(n=12) \\
\text { Mean (SD) }\end{array}$ & $\begin{array}{l}\text { King and Mortenson } \\
(n=11) \\
\text { Mean (SE) }\end{array}$ \\
\hline $\begin{array}{l}\text { Macrophages } \\
\text { Lymphocytes } \\
\text { Neutrophils } \\
\text { Eosinophils } \\
\text { CD4/CD8 ratio } \\
\text { CD577+ natural killer cells (\% lymphocytes) } \\
\text { HLA-DR + activated T cells (\% lymphocytes) }\end{array}$ & $\begin{array}{l}39(19) \\
44(19) \\
10(13) \\
6(8) \\
0 \cdot 6(0 \cdot 5) \\
6(4) \\
16(12)\end{array}$ & $\begin{array}{l}51(27) \\
41(26) \\
4(3) \\
3(6) \\
1 \cdot 1(1 \cdot 1)\end{array}$ & $\begin{array}{r}23(6) \\
14(4) \\
5(2)\end{array}$ \\
\hline
\end{tabular}




\section{LEARNING POINTS}

* BOOP may be a lethal disease in a few patients.

* The prognosis is generally good in most patients, better than that for IPF.

* Risk factors for an unfavourable outcome may include interstitial opacities on radiography, lack of lymphocytosis in BAL fluid, and features of UIP in biopsy specimens.

\section{* Large prospective studies are needed to investigate which group of BOOP patients carries the risk of progressive disease.}

previously associated with BOOP. Indeed, this argument may be reasonable since in Epler's series $^{1}$ the five patients with BOOP and connective tissue disorders also did not recover completely. Katzenstein $e t a l^{3}$ and Guerry-Force et $a l^{4}$ also observed a worse prognosis in those with collagen vascular disease.

On the other hand, other studies have noted a good treatment response in patients with BOOP and rheumatoid arthritis ${ }^{71757}$ or polymyositis/dermatomyositis. ${ }^{18}$ The two larger histopathological studies on lung lesions in these disorders both showed that cases with a BOOP pattern had a more favourable prognosis than those with UIP changes. ${ }^{1718}$ In fact, four of the six patients with primary BOOP in the paper on rheumatoid arthritis ${ }^{17}$ were alive without evidence of pulmonary disease 1-18 years after the biopsy. The two other patients died of unrelated disease when they were both free of pulmonary disease. In the polymyositis series ${ }^{18}$ three of six patients with BOOP were found to be alive and well between two and 18 years after biopsy, one was alive with dyspnoea, and two had died within four weeks of the biopsy from causes probably not related to BOOP (air leak and the adult respiratory distress syndrome, respectively).

Whether the prognosis of BOOP is different in the various types of collagen vascular disease is unclear since, except for the larger series on rheumatoid arthritis and polymyositis detailed above, only sporadic cases have been reported.

Cohen et al speculate whether BOOP was related to extrinsic allergic alveolitis (EAA) in two of their patients who were bird fanciers. BOOP is known to be a secondary histological lesion in patients with EAA. ${ }^{12}$ Other pathological manifestations of EAA were not present in these two patients, so it is unlikely that this was their primary disease.

\section{SMOKING STATUS}

The smoking history was also considered as a potential risk factor for the fulminant course described by Cohen et al, $90 \%$ of their patients being current $(n=4)$ or exsmokers $(n=5)$. In a review of 103 reported cases of idiopathic BOOP only 53 were current or ex-smokers. ${ }^{8}$ This potential relationship needs further confirmation before firm conclusions can be drawn.

\section{Conclusion}

The study by Cohen $e t a l^{51}$ is timely and important. It is the first to underline the fact that BOOP may be a lethal disease in some patients, by describing the clinical and histopathological data of a subset of 10 cases which presented with a fulminant course. It is not clear, however, how often such rapid progression is seen, and what the risk factors are for this unfavourable outcome. Likely candidates are those with a chest radiograph having an interstitial pattern, bronchoalveolar lavage fluid with increases in neutrophils and/or eosinophils without lymphocytosis, and a biopsy specimen with features of UIP and BOOP. Because these characteristics are similar to IPF, the possibility arises that these progressive cases are "hybrids" between BOOP and IPF. Whether or not BOOP associated with connective tissue disorders has a worse prognosis than idiopathic cases is less clear.

Cohen et al recommend that BOOP should be considered in the diagnosis of progressive alveolar infiltrates in the critically ill patient with an appropriate clinical history. In such patients lung biopsy studies should be done early and treatment with corticosteroids started immediately with the aim of preventing the progression of BOOP to end-stage fibrosis. How long treatment should be continued after initial recovery in BOOP to prevent a relapse has not been investigated by controlled prospective studies. Such multicentre studies with large numbers of patients are clearly needed before definite conclusions can be drawn on treatment response, relapse rates, and risk factors to define the subset of patients with BOOP who have a poor response to treatment and a high mortality.

1 Epler GR, Colby TV, McLoud TC, Carrington CB, Gaensler EA. Bronchiolitis obliterans organizing pneumonia. $N$ Engl f Med 1985; 312:152-8.

2 ChandlerPW, Shin MS, Friedman SE, Myers JL, Katzenstein ALA. Radiographic manifestations of bronchiolitis obliterans with organizing pneumonia vs. usual interstitial pneumonia. $A f R$ 1986;147:899-906

3 Katzenstein ALA, Myers JL, Prophet WD, Corley IS, Shin MS. Bronchiolitis obliterans and usual interstitial pneumonia: a comBronchiolitis obliterans and usual interstitial pneumonia: a com-
parative clinicopathologic study. Am $\mathcal{F}$ Surg Pathol 1986;106:373-81.

4 Guerry-Force ML, Muller NL, Wright JL, et al. A comparison of bronchiolitis obliterans with organizing pneumonia, usual interstitial pneumonia and small airways disease. Am Rev Respir Dis 1987;135: 705-12.

5 Cordier JF, Loire R, Brune J. Idiopathic bronchiolitis obliterans organizing pneumonia. Definition of characteristic clinical profiles in a series of 16 patients. Chest 1989;96:999-1004.

6 Izumi T, Kitaichi $M$, Nishimura $K$, Nagai S. Bronchiolitis obliterans organizing pneumonia. Clinical features and differential diagnosis. Chest 1992;102:715-9.

7 Yamamoto $M$, Ina Y, Kitaichi $M$, Harasawa $M$, Tamura M. Clinical features of BOOP in Japan. Chest 1992;102.21,

8 King TE, Mortenson RL. Cryptogenic organizing pneumonitis. The North American Experience. Chest 1992;102:8s-13s. ostabel U, Teschler H, Schoenfeld B, et al. BOOP in Europe. Chest 1992;102:14s-20s.

10 Lee KS, Kulinig P, Hartman TE, Müller NL. Cryptogenic organizing pneumonia: CT findings in 43 patients. $A f R$ 1994;162:543-6.

11 Costabel U, Guzman J. BOOP: what is old, what is new? Eur Respir $f$ 1991;4:771-3

12 Colby TV. Pathologic aspects of bronchiolitis obliterans organizing pneumonia. Chest 1992;102:38s-49s. 
13 Davison AG, Heard BE, McAllister WAC, Turner-Warwick MEH. Cryptogenic organizing pneumonitis. $Q \mathcal{F}$ Med 1983;52:382-93.

14 Geddes DM. BOOP and COP. Thorax 1991;46:545-7.

15 Liebow AA, Carrington CB. The interstitial pneumonias. In: Simon M, Potchen EJ, LeMay M, eds. Frontiers of pulmonary radiology. New York: Grune and Stratton, 1969:102-41.

16 Lange W. Über eine eigenthümliche Erkrankung der kleinen Bronchien und Bronchiolen. Dtsch Arch Klin Med 1901;70:342-64.

17 Yousem SA, Colby TV, Carrington CB. Lung biopsy in rheumatoid arthritis. Am Rev Respir Dis 1985;131:770-7.

18 Tazelaar HD, Viggiano RW, Pickersgill J, Colby TV. Interstitial lung disease in. polymyositis and dermatomyositis. Clinical features and prognosis as correlated with histologic findings. Am Rev Respir Dis $1990 ; 141: 727-33$

19 Gammon RB, Bridges TA, Al-Nezir H, Alexander CB, Kennedy JI. Bronchiolitis obliterans organizing pneumonia associated with systemic lupus erythematosus. Chest 1992;102:1171-4.

20 Bridges AJ, Hsu KC, Dias-Arias AA, Chechani V. Bronchiolitis obliterans organizing pneumonia and scleroderma. F Rheumatol 1992; 19:1136-40.

21 Matteson EL, Ike RW. Bronchiolitis obliterans organizing pneumonia and Sjögren's syndrome. $\mathcal{F}$ Rheumatol 1990;17:676-9.

22 Case record of the Massachusetts General Hospital (case 24-1986). $N$ Engl ₹ Med 1986;314:1627-35.

23 Robinson BW, Sterrett G. Bronchiolitis obliterans associated with polyarteritis nodosa. Chest 1992;102:309-11.

24 Swinburn CR, Jackson CJ, Cobden I, Ashcroft T, Morritt GN. Bronchiolitis obliterans organizing pneumonia in a patient with ulcerative colitis. Thorax 1988;43:735-6.

25 Winterbauer RH, Wilske KR, Wheelis RF. Diffuse pulmonary injury associated with gold treatment. $N$ Engl F Med 1976;294:919-21.

26 Hollingsworth HM. Drug-related BOOP. In: Epler GR, ed. Diseases of the bronchioles. New York: Raven Press, 1994:367-76.

27 Camus P, Lombard JN, Rerrichon M, et al. Bronchiolitis obliterans organising pneumonia in patients taking acebutolol or amiodarone. Thorax 1989;44:711-5.

28 Ogata K, Koga T, Yagawa K. Interferon-related bronchiolitis obliterans organizing pneumonia. Chest 1994;106:612-3

29 Mar KE, Sen P, Tan K, Krishnan R, Ratkalkar K. Bronchiolitis obliterans organizing pneumonia associated with massive L-tryptophan ingestion. Chest 1993;104:1924-6.

30 Patel RC, Dutta D, Schonfeld SA. Free-base cocaine use associated with bronchiolitis obliterans organizing pneumonia. Ann Intern Med 1987;107:186-7.

31 Allen JN, Wewers MD. HIV-associated bronchiolitis obliterans organizing pneumonia. Chest 1989;96:197-8.

32 Kaufman J, Komorowski R. Bronchiolitis obliterans organizing pneumonia in common variable immunodeficiency syndrome. Chest 1991; 102:1895-7.

33 Kaufman J, Komorowski R. Bronchiolitis obliterans. A new clinicalpathologic complication of irradiation pneumonitis. Chest 1990;97: 1243-4.

34 Tobias ME, Plit M, Clinic B. Bronchiolitis obliterans organizing pneumonia with migratory infiltrates: a late complication of radiation therapy. $A f R$ 1993;160:205-6.

35 Crestani B, Kambouchner M, Soler P, et al. Migratory bronchiolitis obliterans organizing pneumonia after unilateral radiation therapy for breast carcinoma. Eur Respir f 1995;8:318-21.
36 Bayle JY, Nesme P, Bjui-Thivolet F, Loire R, Gurin JC, Cordier JF. Migratory organizing pneumonitis "primed" by radiation therapy. Eur Respir f 1995;8:322-6.

37 Tenholder MF, Becker GL, Cervoni MI. The myelodysplastic syndrome and bronchiolitis obliterans. Ann Intern Med 1990;112:714-5.

38 Yale SH, Adlakaha A, Sebo TJ, Ryu JH. Bronchiolitis obliterans organizing pneumonia caused by plasmodium vivax malaria. Chest 1993; 104:1294-6.

39 Thirman MJ, Devine SM, O'Toole $\mathrm{K}$, et al. Bronchiolitis obliterans organizing pneumonia as a complication of allogeneic bone marrow transplantation. Bone Marrow Transplant 1992;10:307-11.

40 Spiteri MA, Klenerman P, Sheppard MN. Seasonal cryptogenic organizing pneumonia with biochemical cholestasis: a new clinical entity. Lancet 1992:340:281-4.

41 duBois RM, Geddes DM. Obliterative bronchiolitis, cryptogenic organizing pneumonitis, and bronchiolitis obliterans or bronchiolitis obliterans organizing pneumonia: three names for two different conditions. Eur Respir f 1991;4:774-5.

42 Geddes DM, Corrin B, Brewerton DA. Progressive airway obliteration in adults and its association with rheumatoid disease. $Q \mathcal{F}$ Med 1977; 46:427-44.

43 Turton CW, Williams G, Green M. Cryptogenic obliterative bronchiolitis in adults. Thorax 1981;36:805-10.

44 Halpin DMG, Geddes DM. Rheumatoid arthritis and connective-tissue disease related bronchiolitis obliterans. In: Epler GR, ed. Diseases of disease related bronchiolitis obliterans. In: Epler GR,
the bronchioles. New York: Raven Press, 1994:231-40.

45 Roca J, Granena A, Rodriguez-Rosin R. Fatal airway disease in an adult with chronic graft-versus-host disease. Thorax 1982;37:77-8.

46 Chan CK. Bone marrow transplantation bronchiolitis obliterans. In: Epler GR, ed. Diseases of the bronchioles. New York: Raven Press, 1994:247-57.

47 Burke CM, Theodore J, Baldwin JC, et al. Twenty-eight cases of human heart-lung transplantation. Lancet 1986;i:517-9.

48 Epler GR. Drug-related bronchiolitis obliterans. In: Epler GR, ed. Diseases of the bronchioles. New York: Raven Press, 1994:241-6.

49 Coultas DB, Funk LM. Postinfectious bronchiolitis obliterans. In: Epler GR, ed. Diseases of the bronchioles. New York: Raven Press, 1994: 215-29.

50 Gosink BB, Friedman PJ, Liebow AA. Bronchiolitis obliterans: roentgenographic-pathologic correlation. AfR 1973;117:816-32.

51 Cohen AJ, King TE, Downey GP. Rapidly progressive bronchiolitis obliterans with organizing pneumonia. Am $\mathcal{f}$ Respir Crit Care Med 1994;149:1670-5.

52 Bartter T, Irwin RS, Nash G, Balikian JP, Hollingsworth HH. Idiopathic bronchiolitis obliterans organizing pneumonia with peripheral infiltrates on chest roentgenogram. Arch Intern Med 1989;149:273-9.

53 Miyagawa Y, Nagata N, Shigematsu N. Clinicopathological study of migratory lung infiltrates. Thorax 1991;46:233-8.

54 King TE. BOOP: an important cause of migratory pulmonary infiltrates? Eur Respir 7 1995;8:193-5.

55 Costabel U, Teschler H, Guzman J. Bronchiolitis obliterans organizing pneumonia (BOOP): the cytological and immunocytological profile of bronchoalveolar lavage. Eur Respir f 1992;5:791-7.

56 Nagai S, Aung H, Tanaka S, et al. Bronchoalveolar lavage cell findings in patients with BOOP and related diseases. Chest 1992;102:32s-37s

57 Rees JH, Woodhead MA, Sheppard MN, DuBois RM. Rheumatoid arthritis and cryptogenic organising pneumonitis. Respir Med 1991; 85:243-6. 